\title{
LA SITUACIÓN JURÍDICA DE DEBER EN EL ARTÍCULO 44 DE LA CONSTITUCIÓN URUGUAYA
}

OBLIGATION LEGAL STATUS UNDER SECTION 44 OF THE URUGUAYAN CONSTITUTION

\section{A SITUAÇÃO JURÍDICA DE DEVER NO ARTIGO 44 DA CONSTITUIÇÃO URU- GUAIA}

Andrea Canabal Mermot*

RESUMEN. La Constitución uruguaya consagra el derecho-deber a la salud. En el presente artículo, la autora se propone estudiar el alcance del artículo 44 de la Constitución uruguaya, respecto del deber consagrado como una situación jurídica. Se estudia el deber en el derecho internacional de los derechos humanos, su relación con la Constitución uruguaya, y la implicancia de este concepto, referido a la salud ante la situación de la pandemia mundial conocida como COVID-19.

PALABRAS CLAVE. Constitución. Artículo 44. Situación jurídica. Deber. Salud.

ABSTRACT. The right-obligation to health is enshrined in the Uruguayan Constitution. In this paper, the author attempts to explore the scope of Section 44 of the Uruguayan Constitution with regard to obligations enshrined as legal status. The paper studies obligations in International Human Rights Law, its connection with the Uruguayan Constitution and the implications of the concept as related to health within the context of the global pandemic known as COVID-19.

KEY WORDS. Constitution. Section 44. Legal status. Obligation. Health.

RESUMO. A Constituição uruguaia consagra o direito-dever à saúde. No presente artigo, a autora propõe-se estudar o alcance do artigo 44 da Constituição uruguaia, em relação ao dever consagrado como uma situação jurídica. Estuda-se o dever no direito internacional dos direitos humanos, sua relação com a Constituição uruguaia e a implicância deste conceito, referida à saúde perante a situação da pandemia mundial conhecida como COVID-19.

PALAVRAS-CHAVE. Constituição. Artigo 44. Situação jurídica. Dever. Saúde.

\footnotetext{
* Asistente (Grado 2), interina, de Derecho Constitucional. Ayudante (Grado 1), interina, de Derechos Humanos. Aspirante a Profesora Adscripta de Derecho Constitucional y de Derechos Humanos. Facultad de Derecho, UDELAR. Miembro Asociada del Instituto de Derecho Constitucional y del Instituto de Derechos Humanos. Doctora en Derecho y Ciencias Sociales. andrea.canabal@gmail.com.
} 


\section{I.- INTRODUCCIÓN}

La situación sanitaria mundial producto de la pandemia provocada por el virus Covid-19, ha evidenciado la necesidad de acciones conjuntas tensionando todos los canales de coordinación internacional con vistas a un objetivo común de protección y cuidado de la vida humana. Los Estados, siguiendo en su mayoría los criterios orientadores de las autoridades científicas, sujetan a las personas a ciertas conductas concretas, que los gobernantes entienden como las adecuadas para el control de la enfermedad en cada caso. Ello ha promovido la reflexión sobre las herramientas que el Derecho utiliza para alcanzar los fines que el Estado se ha propuesto, y cómo se despliegan éstas en la vida en sociedad. El objetivo de la presente exposición es ver aspectos prácticos de la situación jurídica de sujeción “deber" en nuestra Constitución, sin abordar las distinciones teóricas, filosóficas o lingüísticas, respecto a deber y obligación. Se propone analizar, cómo el deber de cuidar la salud que nuestra Constitución impone desde 1934, tiene una aplicación concreta frente a la emergencia sanitaria que transitamos. Se aspira también, evidenciar cómo el Derecho Internacional de los Derechos Humanos incorporado a nuestra normativa legislativa se ejecuta en medidas precisas. En suma, se procura hacer visible que no es posible alcanzar la efectividad de los derechos humanos sin establecer un orden social interno e internacional que actúe para favorecerlos, como lo establece el artículo 28 de la Declaración Universal de los Derechos Humanos, lo que implica para todos, cumplir ciertos deberes.

\section{II. - LOS DEBERES EN EL DERECHO INTERNACIONAL DE LOS DERECHOS HUMANOS}

Ernesto GARZÓN VALDÉS, ha diferenciado conceptualmente calamidades y catástrofes, señalando a las primeras como las desgracias, desastres o miserias que resultan de acciones humanas intencionales y a las segundas como aquellas desgracias, desastres o miserias provocados por causas naturales que escapan al control humano (como se cita en THIEBAUT, 2007: 194). El elemento clave de distinción entre ambos conceptos parece centrarse en la intencionalidad del ser humano en causar la "calamidad".

Para nuestras posibilidades, el estudio de si la pandemia - así calificada por la OMS- por la que atraviesa la humanidad por obra del virus Covid-19, expandida de oriente a occidente, tan universal como democrática, (evidencia de la fragilidad de la vida humana que sin diferencias de sexo, raza, religión o condición social es atacada), es producto de un acto intencional del ser humano, o de la distracción o falta de cuidado sin una deliberada voluntad de provocar tales consecuencias, queda en la mera especulación, sin posibilidad cierta de ser analizada ni de atribuir responsabilidades o culpas a Estados, personas o 
grupos de personas.

Sin poder determinarse -al menos por ahora- si se trata de una calamidad o de una catástrofe, lo cierto es que tanto los gobiernos, como las personas, hemos debido cumplir con nuestros deberes con mayor precisión y exigencia, como contrapartida para la salvaguarda de bienes que son valiosos para la humanidad en general, la vida, la salud, y también la economía como presupuesto para ser viable y digna la vida, ante la situación que nos envuelve. Si bien es cierto que el cumplimiento es siempre exigible, nuestras "deudas" individuales quedan muchas veces ocultas o disimuladas cuando el crédito que tiene el otro u otros o la sociedad en general, es cubierto por un tercero, o el "daño" por el incumplimiento que no es apreciable o cuantificable. Ese débito general de contribuir a la sociedad no necesariamente es estimable por dicha sociedad, esa insuficiencia de contribución -aún con cierto grado de relevancia, por su volumen o por el transcurso del tiempo-, queda como un ingrediente, en fenómenos multicausales, como pueden ser el desempleo o la inseguridad. Sin embargo, pocas veces las personas nos preguntamos si podemos colaborar en algo más con el bienestar de la sociedad en que vivimos. Esta pandemia, no obstante, nos ha exigido cumplir con ciertos deberes que hacen al crédito social. Nos ha exigido el cumplimiento de una conducta más cuidadosa de lo habitual con respecto a la propia salud, para evitar - por ejemplo- que las instituciones de asistencia médica no se vieran desbordadas por la demanda.

Tal como lo establece el numeral $1^{\circ}$ del artículo 29 de la Declaración Universal de los Derechos Humanos (DUDH), de 10 de diciembre de 1948, "Toda persona tiene deberes respecto de la comunidad, puesto que solo en ella puede desarrollar libre y plenamente su personalidad". ARISTÓTELES decía que quien no puede vivir en sociedad o no necesita de ésta, no es miembro de la sociedad, sino una bestia o un dios. (ARITOTELES, S/F). Los derechos del hombre se tienen en relaciones de alteridad frente a otro u otros, cargados con obligaciones, deberes o responsabilidades (BIDART, 1989: 18). Como señala BIDART CAMPOS, "la ilación de las obligaciones con los derechos para que éstos encuentren un sujeto pasivo o varios, que, en satisfacción de esos derechos, tengan que cumplir uno o más deberes, es imprescindible", (BIDART, 2007: 115-116). Así las prestaciones debidas según sea el contenido del derecho, civil, social, económico, serán de abstención u omisión, de dar o de hacer.

El artículo 25 de la DUDH en su numeral $1^{\circ}$ reconoce que, "Toda persona tiene derecho a un nivel de vida adecuado que le asegure, así como a su familia, la salud y el bienestar, y en especial la alimentación, el vestido, la vivienda, la asistencia médica y los servicios sociales necesarios; tiene asimismo derecho a los seguros en caso de desempleo, enfermedad, invalidez, viudez, vejez u otros casos de pérdida de sus medios de subsistencia por circunstancias independientes de su voluntad."

GARZÓN VALDÉS se refiere a las obligaciones que emergen de este artículo 25 como 
“deberes positivos generales". Esta categoría de deberes "son aquellos cuyo contenido es una acción de asistencia al prójimo que requiere un sacrificio trivial y cuya existencia no depende de la identidad del obligado ni de la del (o de los) destinatario (s) y tampoco es el resultado de algún tipo de relación contractual previa" (GARZÓN, 1986). Se trataría en definitiva de una forma de deberes prestación de carácter individual, en virtud de la naturaleza del derecho correlativo, "derecho a un nivel de vida adecuado que... asegure...la salud" entre otros. En la situación extraordinaria de pandemia señalada, siguiendo esta línea de pensamiento, cada persona daría satisfacción a ese derecho efectuando un "sacrificio trivial" de su libertad personal, por ejemplo, al utilizar ciertos artículos en su indumentaria que en situaciones comunes u ordinarias no utilizaría, como pueden ser guantes o tapabocas en el ascensor del edificio donde vive con lo que contribuirá a asegurar la salud de sus vecinos.

Los "deberes negativos" serían por el contrario los deberes de abstención en relación con los derechos de los otros, el "no dañar", no interferir en el ejercicio del derecho ajeno, sintéticamente consistiría en el respeto a la libertad e igualdad de los demás.

PECES-BARBA (2004:179) también hace referencia a los “deberes positivos generales", pero dice "que corresponden directamente a los poderes públicos o que éste atribuye a terceros, personas físicas o jurídicas." El autor explica que estos deberes positivos tienen fundamento en el valor solidaridad, y que en base a este valor o principio se justifica la intervención para crear condiciones para la autonomía moral de la persona. Podemos agregar que la intervención de una acción positiva actual no necesariamente tiene un correlativo derecho en forma simultánea. En tal sentido señala (PECES-BARBA, 2004:179) que “... este efecto especial de la solidaridad que llega a los derechos partiendo de los deberes que genera, permite la comprensión de las construcciones que prolongan la solidaridad en relación a las generaciones futuras. Sobre la base del valor solidaridad hay deberes actuales cuyo cumplimiento beneficiará a las generaciones futuras, pero no hay derechos sino de las generaciones presentes". Se entiende que la misma "construcción" vale para los deberes negativos generales, por ejemplo, el no uso de ciertos productos químicos o determinadas técnicas de cultivo.

La Declaración Americana de Derechos y Deberes del Hombre, en su artículo 11, "Derecho a la preservación de la salud y al bienestar", establece que: "Toda persona tiene derecho a que su salud sea preservada por medidas sanitarias y sociales, relativas a la alimentación, el vestido, la vivienda y la asistencia médica, correspondientes al nivel que permitan los recursos públicos y los de la comunidad.", en este último término "comunidad" podemos encontrar esa cuota parte de deber positivo genérico que cada uno tiene para la preservación de la salud de cada persona en la sociedad.-

No obstante, la Declaración Americana destina un capítulo a los Deberes, entre ellos los que se alinean a nuestras reflexiones son: el artículo 29 "Deberes ante la sociedad. Toda 
persona tiene el deber de convivir con las demás de manera que todas y cada una puedan formar y desenvolver integralmente su personalidad."; artículo 33 "Deber de obediencia a la Ley. Toda persona tiene el deber de obedecer a la Ley y demás mandamientos legítimos de las autoridades de su país y de aquél en que se encuentre."; y artículo 35 "Deberes de asistencia y seguridad sociales. Toda persona tiene el deber de cooperar con el Estado y con la comunidad en la asistencia y seguridad sociales de acuerdo con sus posibilidades y con las circunstancias." En definitiva, estos deberes imponen comportamientos solidarios específicos, donde la contribución personal es valiosa para la vida comunitaria, sin perjuicio de las responsabilidades que en todo caso de desventaja caben a los poderes públicos en un Estado Social de Derecho, para alcanzar el nivel máximo posible de "salud y bienestar".

Asimismo, la Convención Americana de Derechos Humanos (Pacto de San José de Costa Rica) establece en su artículo 32 "deberes" para las personas, en tal sentido preceptúa: "1. Toda persona tiene deberes para con la familia, la comunidad y la humanidad. 2. Los derechos de cada persona están limitados por los derechos de los demás, por la seguridad de todos y por las justas exigencias del bien común, en una sociedad democrática." Puede afirmarse que dichos deberes con la comunidad y la humanidad involucran en lo que a este estudio respecta, el de actuar en beneficio de la salud colectiva, por ejemplo, adoptando las medidas que las autoridades sanitarias locales y mundiales han exhortado practicar, incluso las que imponen abstenciones. Así también, las limitaciones a la libertad en virtud de los derechos de los otros, la seguridad de todos y el bien común, imponen en esta circunstancia, como por ejemplo, distanciamiento físico, aislamiento o suspensión de vuelos turísticos.

Sin perjuicio de que no constituye un documento vinculante, la Declaración de Valencia de 1998 “Declaración de responsabilidades y deberes humanos”, afirma en su preámbulo que la asunción de las obligaciones y responsabilidades implícitas en los derechos humanos y libertades fundamentales recae en todos los miembros individuales de la familia humana, además de Estados y organizaciones. En tal sentido establece, que los miembros de la comunidad mundial tienen responsabilidades y deberes colectivos e individuales de promover el respeto universal, así como la observancia de los derechos humanos y las libertades fundamentales y que todas las personas, pueblos y comunidades, en ejercicio de sus derechos y libertades, tienen la obligación y la responsabilidad de respetar los de los demás y la obligación de tratar de promover y observar tales derechos y libertades.

\section{3.- LOS DEBERES EN NUESTRA CONSTITUCIÓN}

Ahora bien, sin perjuicio de los deberes y obligaciones de "los miembros de la "comunidad" como "colectividad mundial" tanto sean estos "colectivos" como "individuales" 
que surgen de los documentos que conforman el Derecho Internacional de los Derechos Humanos, los Estados y también las personas debemos cumplir una serie de "deberes" que se encuentran positivizados en algunas normas internacionales -como anotáramos - y también en las constituciones, los que en gran parte coinciden expresa o implícitamente con los que emanan de aquellos.

Señalan García de Enterría y Fernández (1981:34). que “es usual que las normas constitucionales impongan deberes públicos a los ciudadanos al propio tiempo que reconocen derechos y libertades que corresponden a éstos pero que entre aquellos deberes y estos derechos no existe ninguna correlación necesaria", y refiriéndose a la Constitución española expresan que se "tipifican los distintos deberes con plena independencia de los derechos que en la propia Constitución se reconocen, relacionándolos pura y simplemente con las potestades públicas destinadas a asegurar su cumplimiento". Aluden a los distintos tipos de deberes ejemplificándolos, de carácter negativo como el sometimiento a la Constitución, de carácter positivo como el servicio militar o prestaciones personales, poderes-deberes como trabajar o educarse, pero explican: “... Lo que importa retener es que en todos estos casos la articulación del contenido y alcance de los deberes exige una cobertura a nivel de la Ley formal ...”. Así lo expresa la Constitución española con relación al servicio militar o al sostenimiento de los gastos públicos. Respecto a la salud el artículo 43 de la Constitución española reconoce el derecho a su protección, pero será la ley la que establezca los derechos y deberes de los servicios públicos prestacionales: "Compete a los poderes públicos organizar y tutelar la salud pública a través de medidas preventivas y de las prestaciones y servicios necesarios. La ley establecerá los derechos y deberes de todos al respecto."

La "Teoría Pura del Derecho" “...coloca en primer plano la noción de deber jurídico". Afirma KELSEN (1979:121) que "el deber jurídico no es otra cosa que la misma norma jurídica considerada desde el punto de vista de la conducta que prescribe a un individuo determinado... Un individuo está jurídicamente obligado a adoptar una conducta determinada en la medida en que una norma jurídica hace de la conducta contraria la condición de un acto de coacción llamado sanción".

Así pues, según la mencionada postura positivista si la conducta contraria a la determinada por la norma no tiene la condición de un acto de coacción, el deber no sería jurídico. Pero tratándose de un deber impuesto por la Constitución, aunque la misma no prevea la sanción y ésta sea objeto de norma legal, tal como lo expresan GARCÍA DE ENTERRÍA Y FERNÁNDEZ, (en nuestra Constitución artículo 85 numeral 20, sin perjuicio de lo establecido por los artículos 256 y siguientes), no podemos entenderlo como carente de carácter jurídico y considerarlo por tanto solamente como ético o moral. La fundamentación de la existencia de estos deberes constitucionales sí la podemos afincar en cuestiones axiológicas o ideológicas, u otras, según la postura que se adopte al respecto (PONCE DE 
LEÓN, 2017), pero no resultaría admisible entender que la Constitución no les atribuye el carácter de "deber jurídico" cuando expresa por ejemplo en nuestro artículo 44 inciso segundo: "Todos los habitantes tienen el deber de cuidar su salud, así como el de asistirse en caso de enfermedad".

La conducta contraria al deber impuesto será siempre una infracción contra la Constitución, aun cuando el legislador no haya previsto el acto de coacción y aun cuando en los hechos la eventual satisfacción correlativa a dicho deber quede a cargo de otros que quien es el directo sujeto pasivo. Pensemos en aquella persona sana física y mentalmente, que no quiere trabajar ni realizar ninguna actividad que signifique aplicar sus energías en forma que redunde en beneficio de la colectividad -tal como lo prescribe el artículo 53 de nuestra Constitución- y vive gracias a la caridad de familiares y amigos. No se tratará solamente de un deber moral o ético, será siempre un deber jurídico en tanto emana de la Constitución, que no es otra cosa que la expresión del ejercicio democrático de una comunidad que ha decidido libre y voluntariamente organizarse como Estado. El consentimiento democrático que da origen a la Constitución, es la base de la obligatoriedad de sus preceptos.

De la lectura de nuestra Constitución surge que el constituyente ha impuesto deberes en forma explícita en algunos artículos y en forma implícita en otros. Así son ejemplo de deberes explícitamente impuestos los que surgen de los artículos 41 y 42 a cargo de los padres con relación a sus hijos. En ese sentido el artículo 44 para todo habitante con respecto a su salud y asistencia, el artículo 53 a todo habitante el deber de aplicar sus energías en forma que redunde en beneficio de la colectividad y el artículo 56 a las empresas de proporcionar alimentación y alojamiento a su personal en ciertas circunstancias.

Respecto a los deberes que podemos hallar de manera implícita los artículos son varios, puesto que una norma que reconozca un derecho generará una obligación impuesta a cargo de otro sujeto, aún cuando esta sea la de abstenerse de interferir en el goce o ejercicio del derecho reconocido, o la más genérica de no dañar. En tal sentido podemos ejemplificar citando los artículos 7, 10, 11, 28, 29, 30, 38, sin olvidar el artículo 72 que menciona en forma expresa a los "deberes" no enumerados.

De ello surge que los deberes ya sean implícitos o explícitos pueden consistir -siguiendo el lenguaje de Bidart Campos (1989)- en "a) prestación negativa o de omisión, o de no hacer, b) prestación positiva de dar algo; c) prestación positiva de hacer algo".

\section{4.- EL DEBER DE CUIDAR LA SALUD}

El artículo 44 de nuestra Constitución establece en forma explícita deberes a todos los habitantes con relación a su salud y asistencia, pero impone a la vez, mandatos a los poderes públicos. 
Principiando por estos últimos, diremos que el inciso primero está dirigido al legislador, quien debe legislar en "cuestiones relacionadas con la salud e higiene públicas, procurando el perfeccionamiento físico, moral y social de todos los habitantes del país." Este inciso, fiel reflejo del constitucionalismo social, establece una obligación al Estado legislador, una "prestación positiva de hacer algo", que tiene como fin el perfeccionamiento de la persona en su dimensión individual y social.

El inciso tercero consiste en un mandato al poder administrador, de proporcionar gratuitamente los medios de prevención y de asistencia a los indigentes o carentes de recursos suficientes, "prestación positiva de dar algo". Es muestra del carácter social y humanista de nuestro Estado, que ambos incisos señalen como finalidad a perseguir, la persona humana. Esta última es el fin de la actuación del Estado, pero en el inciso tercero, el constituyente ha puesto mayor énfasis, imponiendo una prestación concreta para quienes se encuentren en situación de carencia económica, "indigentes o carentes de recursos suficientes", es decir, aquellas personas que mayor vulnerabilidad puedan presentar. Abundante jurisprudencia nacional ilustra sobre cómo ha sido obligado al Estado a dar satisfacción a este mandato cuando la aplicación de políticas de salud con relación a medicamentos y tratamientos de alto costo, no resultaron en el cabal cumplimiento del mismo.

El legislador ha dictado una gran cantidad de leyes en materia de salud con el objeto de procurar el perfeccionamiento físico, moral y social de los habitantes.

Ahora bien, ante la situación planteada por el Covid -19, las normas jurídicas que dan fundamento a las medidas implementadas por el Poder Ejecutivo han sido el citado artículo 44 de la Constitución, la Ley Orgánica de Salud Pública № 9.202 de 12 de enero de 1934 y el Reglamento Sanitario Internacional (2005).

La Ley $\mathrm{N}^{\circ} 9.202$ ha establecido la competencia del Poder Ejecutivo por intermedio del Ministerio de Salud Pública, para la organización y dirección de los servicios de Asistencia e Higiene. Así mismo previó los cometidos de dicho Ministerio, específicos en caso de epidemias o de enfermedades infecto-contagiosas, y habilitó al Poder Ejecutivo para disponer la intervención de la fuerza pública e incluso, determinar el aislamiento y detención de las personas que por sus condiciones de salud pudieran constituir un peligro colectivo. En tal sentido, el Poder Ejecutivo en cumplimiento de los cometidos asignados, ha dictado los Decretos 93/020 de 13 de marzo de 2020 y 94/020 de 16 de marzo de 2020, estableciendo la "Declaración de Emergencia Sanitaria", la adopción de medidas como el cierre preventivo de centros turísticos, de lugares de acceso público, la suspensión de espectáculos públicos, y disponiendo el aislamiento de las personas con síntomas de la enfermedad. Se ha hecho efectivo el mandato constitucional de cuidado de la salud de la comunidad, de la salud e higiene públicas, con medidas específicas para las personas que contrajeron la enfermedad para preservar a la sociedad en su conjunto.

Hasta aquí lo relacionado al mandato a los poderes públicos. Como explicamos antes, la 
Constitución impone también en el artículo 44, deberes a las personas.

El inciso segundo del citado artículo 44 establece el deber explícito dirigido a "Todos los habitantes" de "cuidar su salud, así como el de asistirse en caso de enfermedad". Quizá nunca tanto como en este momento ha sido necesario poner énfasis en el cumplimiento de dicho deber. El deber impuesto para el propio cuidado y asistencia, tiene por finalidad también a la persona humana en su doble dimensión, individual y social, la persona como valor en sí misma pero en su dimensión social.

En tal sentido, el cuidado de la propia salud y asistencia es el deber hacia sí mismo, por cuanto asumir un deber para consigo mismo supone reconocer, en la propia persona, la dignidad, el derecho que puede atribuirse en cuanto persona (BEADE, 2017). Podría entenderse entonces, en este aspecto que se trata solamente de un deber moral. Pero afirmamos que la Constitución impone deberes jurídicos. Entonces, jurídicamente el deber de "cuidar su propia salud" debe ser analizado en el contexto de todo el artículo 44. Si el legislador por el inciso primero está mandatado a procurar "el perfeccionamiento físico, moral y social de todos los habitantes", cada habitante debe "cuidar su salud" y "asistirse en caso de enfermedad" procurando idéntico fin. Es "lo suyo" de que habla Germán Bidart Campos (2007: 115), eso "suyo" que es de la persona, el valor, su dignidad humana, que en cuanto derecho reclama cuidado y atención (sea de los demás en general, del Estado, de los prestadores privados que haya contratado) y en cuanto deber se le impone cuidarse y atenderse. Así categorizado por la doctrina como derecho-deber, el derecho al cuidado de su salud y a la asistencia, se ensambla como dice García de Enterría (1981: 29), con el deber de cuidarse y atenderse, que sería no descuidar su salud o no actuar en contra de la propia salud, y la obligación de asistirse en caso de enfermedad.

El mencionado deber de "cuidar su salud" y "asistirse en caso de enfermedad" tiene como se expresaba un doble efecto, pues cada integrante de la sociedad, cada habitante debe cuidar la propia salud, en tanto cada uno es valioso en sí mismo, pero tiene una proyección social en tanto cada persona es integrante del conjunto, cuya perfección procura la Constitución al mandatar al legislador en el inciso primero.

Recogiendo lo señalado por García de Enterría precedentemente, vemos que en el caso de los deberes impuestos con relación a la salud y asistencia, la articulación de su contenido y alcance "exige una cobertura a nivel de la Ley formal".

Así, para entender el contenido y alcance del término "perfeccionamiento", podemos acudir a los artículos 1 y 2 de la Ley $\mathrm{N}^{\circ}$ 18.256, en el marco del derecho al medio ambiente libre de humo de tabaco y su consumo. En esta norma se toma en parte lo preceptuado en el artículo 12 del Pacto Internacional de los Derechos Económicos, Sociales y Culturales. Deviene acertado el camino del legislador, pues en el ejercicio de un anclaje de dicho vocablo "perfeccionamiento", y más allá de las influencias filosóficas contenidas en el mismo (Kant), corresponde tener presente el texto constitucional como un todo y también 
el Derecho Internacional de los Derechos Humanos, y en tal sentido resulta ajustado interpretarlo como el "más alto nivel posible de salud física y mental".

El adjetivo "posible" nos estaría dando el límite de la propia capacidad de cumplir con dicho deber de cuidar la salud. En el caso de la pandemia que motiva estas reflexiones, "cuidar su salud" procurando el más alto nivel posible, estaría significando realizar el mayor esfuerzo por el cumplimiento de las medidas preventivas indicadas, como ser el uso de tapabocas en medios de transporte público, o las de higiene como el lavado frecuente de manos, o el aislamiento dispuesto para quienes presentan síntomas o han contraído el virus Covid-19, en los términos del artículo $8^{\circ}$ del Decreto 93/020.

En cuanto al deber de "asistirse en caso de enfermedad" debe tenerse presente lo reglamentado por las leyes para el derecho a la protección de la salud que tienen todos los habitantes del país y las diversas modalidades para su acceso a servicios integrales de salud, Leyes $\mathrm{N}^{\circ} 18.211$ de 5 de diciembre de 2007 y 18.335 de 15 de agosto de 2008. Con relación a la situación de pandemia, el artículo 10 del referido Decreto 93/020, precisa el alcance, la forma, con las notas de inmediatez y atención domiciliaria que delimita el deber de asistirse: "Las personas que presenten síntomas compatibles con COVID-19 deberán reportarlo de inmediato desde su domicilio a su prestador de salud, y de no poseerlo, a la Administración de los Servicios de Salud del Estado."

Como se trata de un deber jurídico, el medio coactivo para el caso de incumplimiento lo establece la ley penal en el artículo 224 del Código Penal para el caso de daño por violación de las normas sanitarias, así como el artículo 11 del ya citado Decreto para el caso de medidas administrativas. Este último dispone: "En caso de verificarse el incumplimiento de lo dispuesto en los artículos 8 y 10 del presente Decreto, el personal de salud o quien tome conocimiento de lo sucedido deberá comunicarlo de inmediato a la Dirección General de la Salud del Ministerio de Salud Pública, que de entenderlo pertinente dará noticia a su División Servicios Jurídicos a efectos de realizar la denuncia penal correspondiente." Cabe señalar aquí que el artículo $2^{\circ}$ numeral 2 de la Ley $\mathrm{N}^{\circ} 9.202$ prevé que el Poder Ejecutivo, disponga la intervención de la fuerza pública, para garantir el fiel cumplimiento de las medidas que adopte, entre ellas el aislamiento y detención de las personas que por sus condiciones de salud pudieran constituir un peligro colectivo (numeral 3).

Lo expresado anteriormente lleva a concluir que el deber de cuidar la salud y atenderse en caso de enfermedad, en lo relacionado a la pandemia por Covid -19, tiene un alcance determinado que está dado por la Ley $N^{\circ} 9.202$ y por el Decreto 93/020 entre otras normas que regulan aspectos relativos a derechos y deberes de los usuarios del sistema de salud, e inclusive por la ley penal vigente en el caso de producirse un daño por incumplimiento. Puede apreciarse que las medidas están dirigidas a procurar garantizar la salud colectiva, pero cuya efectividad tiene necesariamente en esta situación una primera instancia individual de cumplimiento del deber constitucional. Es el cumplimiento de las personas de 
sus deberes individuales con relación a la comunidad.

\section{5.- JUSTIFICACIÓN DEL DEBER DE CUIDAR LA SALUD}

Resta señalar que, en la búsqueda del valor subyacente a lo planteado, y en tanto la salud de la población hace a la dignidad de los pueblos que, en cuanto personas jurídicas colectivas son también titulares de una dignidad propia (GROS, 2002), la solidaridad parece ser el preponderante.

PECES-BARBA (2004:166), permite comprender por qué entendemos a la solidaridad como la base valorativa del deber de cuidar la salud que la Constitución nos impone al expresar que a "diferencia de los demás valores que fundamentan directamente derechos, la solidaridad lo hace indirectamente por el intermedio de los deberes", Es que la solidaridad se integra con la idea del ser humano como fin en sí mismo, y por tanto con los valores de libertad e igualdad, bases de la construcción de los Derechos Humanos, pero superada, vencedora sobre el egoísmo primitivo. Pues tal como lo expresa Peces-Barba (2004:178) su "punto de partida... es el reconocimiento de la realidad del otro y la consideración de sus problemas como no ajenos, sino susceptibles de resolución con intervención de los poderes públicos y de los demás".

El Preámbulo de la Constitución de la Organización Mundial de la Salud ha definido a la salud como un estado de completo bienestar físico, mental y social, y no solamente la ausencia de afecciones o enfermedades. Pero este estado de bienestar es frágil frente a la amenaza que representa el virus Covid-19. La facilidad en su propagación ha puesto de manifiesto que es imprescindible que cada uno adopte las medidas de prevención sobre sí, pero, además, cumplir con las restricciones impuestas por las autoridades públicas para el cuidado de todos.

Entonces, para determinar hasta dónde llega el deber de cuidar la salud y de asistirse en caso de enfermedad, habrá de acudirse en cada caso a las leyes que dan su "contenido y alcance", así como también convenciones internacionales y normas reglamentarias. Determinar en cada caso si prevalece la libertad o el deber de cuidado, cuando se trate de situaciones como someterse a tratamientos médicos dolorosos, a exámenes médicos cuya práctica la persona rechaza por cualquier razón, o si cuidar su salud implica hacerlo de forma obligatoria como lo indica la medicina tradicional y con los métodos convencionales aprobados por las autoridades sanitarias del momento, será finalmente la tarea del juez como lo es para todo conflicto entre derechos y libertades, individuales y colectivos. Pero, frente a situaciones como la que vivimos hoy, donde prevalece lo colectivo con la obligación genérica de no dañar, y las específicas mencionadas precedentemente, nos ubicamos como parte del todo, de una familia, de una comunidad, del Estado y de un espacio universal donde no hay fronteras que impidan la penetración del virus. Nuestra conducta 
personal cuidadosa y atenta en el cumplimiento de los deberes individuales asegura tan solo y no completamente, la integridad del entorno más cercano, sea éste familiar, laboral o simplemente de vecindad, "con el reconocimiento del otro como "prójimo", y como formando parte de nuestra misma comunidad” (PECES-BARBA, 2004: 178).

\section{6.- CONCLUSIONES}

PECES-BARBA expresa: "la última de las preguntas relevantes para comprender a una sociedad política y jurídica bien ordenada. ¿Por qué se obedece?, que tiene el vínculo con la respuesta de los ciudadanos ante el Derecho y ofrece buenas razones para defender la obediencia como la opción más razonable en una sociedad abierta y libre". (PECES-BARBA, 2009). Ese vínculo de los ciudadanos ante el Derecho, radica en la idea de soberanía para la formación del mismo, en el cumplimiento de la "primera función" del soberano, como lo señala el autor, que es la de producir el Derecho, con un contenido de valores apoyados en el reconocimiento y respeto de la dignidad humana, para configurar un sistema justo. Un sistema jurídico que sea justo o que "tienda a la justicia" deberá ser siempre un sistema "apoyado en el poder democrático" que le da legitimidad para el monopolio del uso de la fuerza legítima. Es decir, los ciudadanos de una sociedad abierta y libre obedecen razonablemente al Derecho para el que han prestado su consentimiento, y que ha sido creado en valores éticos de convivencia que han quedado así legalizados. Cabe destacar que el artículo 44 que estudiamos, tiene origen en la Constitución de 1934 y la Ley $N^{\circ} 9.202$ es de 12 de enero de 1934. Nuestra Constitución se reformó tres veces desde entonces hasta llegar a la actual de 1967, que por otra parte ha sido sometida a reformas parciales hasta el año 2004. No obstante, el artículo 44 que hemos estudiado ha permanecido. Muchos parlamentos se han sucedido en el tiempo desde 1934 y la Ley $\mathrm{N}^{\circ}$ 9.202 permanece igual en los artículos señalados precedentemente. En definitiva, nuestra comunidad política ha prestado su consentimiento para obedecer el deber impuesto.

También es importante considerar, que nuestra legislación posterior a la señalada antes, se encuentra alineada a las obligaciones emergentes del ámbito internacional por ser estado miembro de la Organización de Naciones Unidas y de la Organización de Estados Americanos, resultando aplicables y ejecutables para los habitantes de la República, los preceptos que los documentos internacionales en materia de derechos humanos establecen, incluidos los deberes que en cada caso se señalaron. Las obligaciones internacionales han sido asumidas por el Estado a través de sus poderes representativos al amparo de la Constitución y forman parte de nuestro ordenamiento de acuerdo a los procedimientos que la misma establece.

En suma, en el camino siempre transitable hacia un Estado de Derecho Sustancial o Democracia Sustancial, el orden jurídico se impone en tanto se funda en el principio de 
legitimidad y está en el consentimiento de todos ubicados en un plano de igualdad y manifestado en libertad.

Pero, corresponde concluir, que, si el orden jurídico así legitimado consagra los derechos, también lo hace respecto de los deberes. Pues, la finalidad de aquel es la persona humana, en su dimensión individual y social, y por tanto la salvaguarda de su dignidad, que "no es otra cosa que el compendio de nuestros derechos, cuya vigencia corresponde reclamar y hacer respetar, y la raíz de nuestros deberes, que es preciso acatar y cumplir" (VIDART, 2003).

\section{BIBLIOGRAFÍA CONSULTADA.}

ARISTOTELES. (S/F). Política. Disponible en: https://www.marxists.org/espanol/tematica/cienpol/aristoteles/pol.pdf. Fecha de consulta: 31 mayo 2020.

BEADE, I. (2017). Acerca de la relación entre "derechos y deberes" en la filosofía práctica kantiana. De la reciprocidad jurídica a la reciprocidad ética. Res Publica. Revista de Historia de las Ideas Políticas. 20 (2), 275-291. Disponible en: https://doi.org/10.5209/ RPUB.56470

BIDART CAMPOS, G. (1989). Teoría General de los Derechos Humanos. México: Universidad Nacional Autónoma de México.

BIDART CAMPOS, G. (2007). Nociones constitucionales: las intersecciones iusnaturalistas de la Constitución. Buenos Aires: EDIAR.

GARZÓN VALDES, E. (1986). Los deberes positivos generales y su fundamentación. DOXA. Cuadernos de Filosofía del Derecho, 3, 17-33. Disponible en: http://dx.doi. org/10.14198/DOXA1986.3.01. Fecha de consulta: 31 mayo 2020.

GARCÍA DE ENTERRIA, E. RAMON FERNANDEZ, T. (1981). Curso de Derecho Administrativo. Volumen II. Madrid: Civitas.

KELSEN, H. (1979). Teoría Pura del Derecho. Buenos Aires: Editorial Universitaria. PECES-BARBA, G. (2009). Reflexiones sobre la Justicia y el Derecho. Derechos y Libertades. 20, 21-36. Recuperado de http://hdl.handle.net/10016/11252. Fecha de consulta: 31 mayo 2020.

PECES-BARBA, G. (2004). Lecciones de Derechos Fundamentales. Madrid: Dykinson. PONCE DE LEÓN, V. (2017). La función de los deberes constitucionales. Revista chilena de Derecho. 44 (1), 133-158. Disponible en: http://dx.doi.org/10.4067/S071834372017000100007. Fecha de consulta: 31 mayo 2020.

THIEBAUT, C. (2007). Calamidades, intencionalidades y daños. DOXA. Cuadernos de Filosofía del Derecho, 30, 193-198. Disponible en: http://dx.doi.org/10.14198/ DOXA2007.30.28. Fecha de consulta: 31 mayo 2020.

VIDART, D. (2003). Sobre la dignidad humana. Montevideo: Cátedra UNESCO de De- 
rechos Humanos.

Referencias normativas.

Organización Mundial de la Salud. (O.M.S.). Constitución. Disponible en: https://www. who.int/governance/eb/who_constitution_sp.pdf?ua=1. Fecha de consulta: 31 mayo 2020.

Organización de las Naciones Unidas. (O.N.U.). Declaración Universal de los Derechos Humanos. 10 de Diciembre de 1948.

U.N.E.S.C.O., Declaración de Responsabilidades y Deberes Humanos. Declaración de Valencia. 1998. Disponible en: https://dhpedia.wikis.cc/wiki/Declaraci\%C3\%B3n_de Responsabilidades_y_Deberes_Humanos\#Contenido_de_la_Declaraci.C3.B3n. Fecha de consulta: 31 mayo 2020.

Uruguay. Ley $\mathrm{N}^{\circ}$ 18.256. Protección del derecho al medio ambiente libre de humo y de tabaco y su consumo. Diario Oficial. 31 de marzo de 2008.

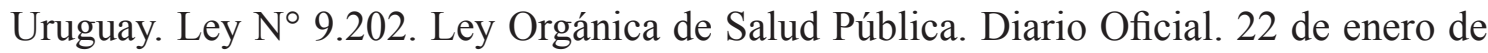
1934.

Fecha de recepción: 31 mayo 2020.

Fecha de aceptación: 20 junio 2020. 